\title{
Carbon Dioxide Emissions: A Dynamic Panel Analysis of Energy Intensive Industries in Egypt
}

\author{
By Iman Al-Ayouty ${ }^{1}$, Hoda Hassaballa ${ }^{2}$, Maha El Hini ${ }^{3}$
}

\begin{abstract}
Most energy intensive industries are high carbon dioxide $\left(\mathrm{CO}_{2}\right)$ emitters. As $\mathrm{CO} 2$ emissions show large discrepancies between regions, it is important to test for spatial dependence when estimating emissions. The present study thus examines spatial dependence of $\mathrm{CO}_{2}$ emissions for the twenty-seven governorates of Egypt over the period 2007-2016. Determinants of $\mathrm{CO}_{2}$ emissions include road network density, investments in fixed assets, the structure of economic activity, the share of females, and the various levels of education in the regions' respective population. Incorporating the spatial dimension, as well as using female and educational levels amongst the determinants, are contributions to research done on $\mathrm{CO}_{2}$ emissions in Egypt. Estimation results indicate that $\mathrm{CO}_{2}$ emissions across governorates are spatially-random rather than spatially-dependent. The study therefore uses a generalized method of moments (GMM) dynamic panel model. The lag of $\mathrm{CO}_{2}$ emissions per capita, net fixed capital formation, share of illiterates in the working age population, and the share of services in economic activity are significant and have positive effects (increasing emissions). The share of females in working age population, and the share of agriculture in economic activity are significant and have negative effects (diminishing emissions). Policy implications based on the study results are given.
\end{abstract}

Keywords: Spatial Analysis, Dynamic Panel Model, Carbon Dioxide Emissions, Energy Intensive Industries, Egypt

\section{Introduction}

Environmental degradation continues to be a threat to sustainability. Factors that contribute to environmental degradation include growth, trade, manufacturing, net fixed capital formation, environmental awareness and gender. The Environmental Performance Index showed that Egypt's rank was 66 in 2018 and slipped down to 94 in 2020 out of 180 countries (Environmental Performance Index in 2018, 2020). This movement may stress the extent to which Egypt continues to rely heavily on energy intensive industries, and has relatively low efficiency in utilising energy sources at the sectoral level (CAPMAS, 2018).

\footnotetext{
| ${ }^{1}$ Assistant Professor of Economics, Faculty of Business Administration and International Trade, Misr International University, Cairo, Egypt; Corresponding Author

${ }^{2}$ Associate Professor of Economics, Department of Economics, Faculty of Business Administration, Economics and Political Science, The British University in Egypt, Suez Desert Road, El Sherouk City, Cairo, Egypt

${ }^{3}$ Lecturer of Economics, Faculty of Business Administration, Economics and Political Science, The British University in Egypt, Suez Desert Road, El Sherouk City, Cairo, Egypt.
} 


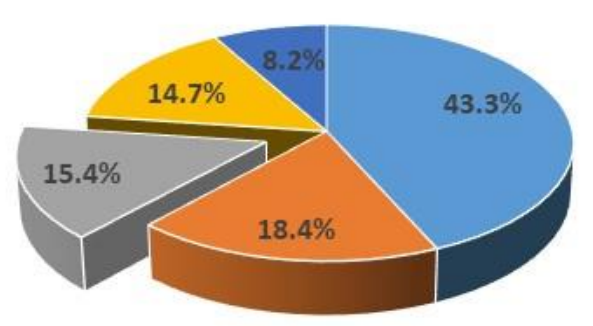

- Electricity (petroleum products consumption)

- Transport

- Industrial sector

= Other sectors

- Domestic and commercial sectors

2018.

Figure 1 below gives the sources of $\mathrm{CO}_{2}$ emissions by sector in Egypt for the year

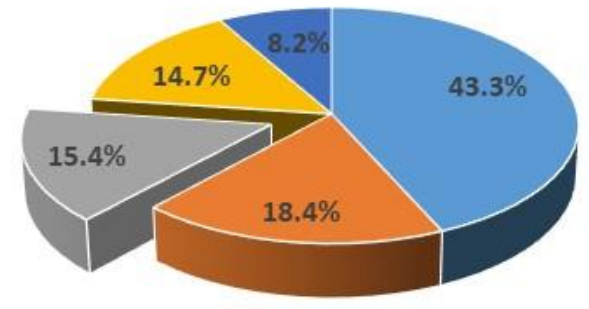

- Electricity (petroleum products consumption)

- Transport

- Industrial sector

- Other sectors

- Domestic and commercial sectors

Figure 1: Sources of CO2 Emissions by Sector in Egypt

Source: (CAPMAS, 2018)

The industrial sector is evidently the third contributor of $\mathrm{CO}_{2}$ emissions in Egypt. It poses as one of the major threats to environmental degradation. Hence, it is crucial to study the determinants of $\mathrm{CO}_{2}$ in energy-intensive industries since they are the high $\mathrm{CO}_{2}$ emitters among industries. This paper aims at analysing the determinants of $\mathrm{CO}_{2}$ emission per capita from polluting- and energy-intensive industries across Egypt's governorates in a panel model which incorporates the spatial dimension over the period 2007-2016. ${ }^{1}$ To the authors' knowledge, this is the first research that studies $\mathrm{CO}_{2}$ emissions from polluting energy-intensive industries at the regional level in Egypt through spatial panel analysis. The

${ }^{1}$ For more information regarding Egypt's governorates, see table A1 in the appendix. 
paper is organised as follows: section two provides the literature review; section three discusses the methodology used and variable description; section four discusses the results; and section five concludes and suggests policy implications.

\section{Literature Review}

The Environmental Kuznets Curve (EKC) hypothesis is commonly used to describe the relationship between economic growth and environmental quality (Cai, 2008; Friedl and Getzner, 2003; Grossman and Krueger, 1991; Lin and Jiang, 2009; Lorember et al., 2020; Panayotou, 1993; Schmalensee et al., 1998). The hypothesis states that the relationship between economic growth and environmental degradation is represented by an inverted U-shape curve (Özokcu and Özdemir, 2017). However, it is criticized for two reasons: first, for excluding other determinants of pollution emissions level; second, for not incorporating the spatial dimension in the analysis which may result in spurious results (Zheng et al., 2014), biased or inconsistent estimators (Burnett and Bergstrom, 2010), and unreliable statistical inference (Zhao et al., 2014).

Spatial dependence is defined as "the propensity for nearby locations to influence each other and to possess similar attributes" (Goodchild, 1992). In general, all spatial data tend to have spatial dependence (Anselin, 1991). Spatial dependence with respect to $\mathrm{CO}_{2}$ emissions is likely to occur when there is degree of cooperation and strong integration between different regions. In addition, because of its gas nature, $\mathrm{CO}_{2}$ can spread easily across regions depending on the wind speed and other weather conditions (Zheng et al., 2014). On the other hand, spatial independence can be an alternative. This can be due to spatial randomness that occurs from having zero spatial autocorrelation. Such cases indicate identically distributed random data that do not vary by geographic location (Gangodagamage et al., 2008). One possible reason for this could be the absence of cooperation and coordination between neighboring regions. Alternatively, $\mathrm{CO}_{2}$ could be distributed homogenously across the whole land area (Goodchild, 1992).

Further important factors that ought to be considered when estimating $\mathrm{CO}_{2}$ emissions is to include the persistence or correction of pollution emissions level. If there is persistence, static models would be misspecified, while dynamic models would be more fitting. Since dynamic models are used when historical values of the dependent variable matter, they would account for the dynamic (intertemporal) feature of sustainability in studying $\mathrm{CO}_{2}$ emissions level. They would also account for the $\mathrm{CO}_{2}$ accumulation in the atmosphere. However, an endogeneity problem arises when using dynamic panel models, as the strict exogeneity of the regressors is violated. Hence, it is essential to tackle the endogeneity problem in dynamic panel models.

In general, externalities, such as the pollution emissions level, tend to have both 'spatial' and 'dynamic' dimensions (Nicolaisen et al., 1991). In addition, Elhorst (2012) stated that both spatial and dynamic effects must be taken into account to avoid biased estimators. In other words, if the spatial effects are considered, while the dynamic effects are omitted, estimators are biased. Likewise, if only dynamic effects are considered, and the spatial effects are omitted, estimators are biased. Hence, a spatial dynamic panel model framework is more suitable in studying $\mathrm{CO}_{2}$ emissions level.

With respect to EKC, Balado-Naves et al. (2018) employ a panel data model on 173 
countries for the period 1990-2014 to test the EKC hypothesis for neighbouring per capita income and energy intensity in Europe, Asia and the World. Empirical results support the standard EKC hypothesis in which neighbouring per capita income and national per capita emissions are exhibiting an inverted U-shaped relationship. A further study by Jeanty et al. (2013) tested the existence of spatial interdependence in the EKC in some European countries between 1961-2009 via panel data model methods. Results of the spatial dynamic panel study indicated the presence of a strong degree of interdependence in $\mathrm{CO}_{2}$ emissions per capita in these European countries under the studied period.

Elliott \& Clement (2014) also studied spatial inequality in $\mathrm{CO}_{2}$ across the United States using a spatial panel regression model with two-way fixed effects. The study used integrated county-level environmental data, residential and industrial emissions along with demographic and economic data. Results revealed spatial segregation between carbonintensive production and socio-environmental interactions within as well as across societies, as industrial combustion and urban cities grow. Furthermore, Fang et al. (2015) propose that determinants contributing to increasing $\mathrm{CO}_{2}$ in the $\mathrm{G}-20$ countries include population growth and economic growth, while increases in energy efficiency contribute to reducing carbon emissions level.

Liu \& Zhao H (2012) analyse the regional distribution of $\mathrm{CO}_{2}$ intensity in China, showing that emissions are unbalanced across regions, but increasing over time. Fan and Liu (2012) as cited in Zheng et al. (2014) propose that there is direct relationship between $\mathrm{CO}_{2}$ intensity and the degree of industrialization and the provincial industrial composition. They used the Theil index and spatial autocorrelation to find that the $\mathrm{CO}_{2}$ intensity across 8 economic zones in China between 1999 and 2007 are clustered in three zones that are related on the provincial level. Further studies applying spatial autocorrelation and multi regression methods include Dong and Liang, (2014) as cited in (Azimi \& Yang, 2018), tested how technology upgrading constraints across 30 provinces in China may contribute to regional disparities in emission patterns. Three main air pollutants, namely, Sulphur dioxide $\left(\mathrm{SO}_{2}\right)$, Nitrogen oxide (NO) and $\mathrm{CO}_{2}$ were used in the study to analyse environmental discrepancy and inequity across regions using the Lorenz curve and the Gini coefficient. Results showed cluster effects and regional discrepancies in air pollutants where the richer and the relatively more industrialised regions in the Eastern provinces of China, give lower emissions. On the other hand, higher emissions are found in less developed Central and Western regions. Poorer regions of China are shown to struggle while attaining the necessary funds for pollution control. (Azimi \& Yang, 2018).

A study by Cole et al. (2013) calculated how Japanese firms are influenced by neigbouring fims' contribution to $\mathrm{CO}_{2}$ emissions. The main determinants of firms' emissions used in the study are: the capital-labour ratio, firm size, expenditure on research and development, advertising expenditure, and exports as a share of output. Results showed that firm size is a critical determinant of $\mathrm{CO}_{2}$ emissions, where large firms produce lower emissions per unit of output by using abatement activity. The study thus suggests that firms do not operate in isolation of each other, but they influence each other through imitation and demonstration effects, and through competitive pressures.

With reference to India, Paul and Bhattacharya (2004) determine the factors influencing changes in $\mathrm{CO}_{2}$ emissions in India at the aggregated and the disaggregated levels. The study uses the decomposition technique developed by Sun (1998) to gauge changes in energy 
consumption over time. The study considers four different factors: changes in carbon dioxide emissions; the pollution coefficient effect; the intensity effect; and the structural and activity effects (Paul and Bhattacharya, 2004). Results show that the pollution coefficient effect, the energy intensity effect, the structural effect and the economic activity effect are the major factors that cause an escalation in $\mathrm{CO}_{2}$ emissions. The study further shows that economic growth is a key contributor to increasing $\mathrm{CO}_{2}$ emissions in the agricultural, industrial and transport sectors in India (Paul and Bhattacharya, 2004).

Also using decomposition analysis, Akbostanc1 et al. (2011) study the $\mathrm{CO}_{2}$ emissions in the Turkish manufacturing industry using fuel consumption data covering 57 industries between 1995 and 2001. The study uses a decomposition of the changes in the $\mathrm{CO}_{2}$ emissions of manufacturing industry into 5 components. Their findings indicate that changes in $\mathrm{CO}_{2}$ emissions are mainly driven by the changes in total industrial activity and energy intensity during the study period.

With reference to countries of the Far East, a study by Anwar, Younis and Ullah (2020) studies the main determinants of $\mathrm{CO}_{2}$ emissions in Far East countries between 1980-2017, by adopting panel data fixed effects model. The study shows that urbanization level, economic growth and trade openness are the main determinants of CO2 emissions in the selected countries.

Xiaoyan et al. (2013) use a dynamic spatial system-GMM panel approach on Chinese provincial data from 1995-2009 to study China's industrial transformation and $\mathrm{CO}_{2}$ emissions. Results show that transformation of China's industrial structure led to a reduction in $\mathrm{CO}_{2}$ emissions and that knowledge- and technology-intensive industries have lower $\mathrm{CO}_{2}$ emissions due to their limited energy consumption. The study further shows that China's current technical progress was not the reason behind reducing $\mathrm{CO}_{2}$ emissions, but that advancement and optimization of the industrial structure was the main determinants. A dynamic spatial panel model is also used by Zhao, Burnett, \& Lacombe, (2015) to test the convergence of $\mathrm{CO}_{2}$ intensities for 30 Chinese provinces between 19902010. Results show that $\mathrm{CO}_{2}$ emissions are converging across Chinese provinces with a positive spatial correlation.

The following section discusses the methodology and results of testing for spatial dependence of $\mathrm{CO}_{2}$ emissions for Egypt's industrial sector at the governorate level.

\section{Methodology}

Cross-sectional spatial econometric analysis relies on studying spill-over effects amongst neighbouring regions (i.e., spatial dependence). It is very important to test for spatial dependence in order to prevent bias (Nsiah and Wu, 2014) and inefficiencies in parameter estimates (Jeetoo, 2020). To account for spatial dependence, a binary 'contiguity weight matrix' uses the geographical attributes of region(s) to identify their neighbourhood. The diagonal zero element in the matrix are those of each region being its own self. The off-diagonal elements are 1 for those regions it neighbours. The weight matrix is then transformed by row-standardizing whereby each element in the row is divided by the sum of row elements ${ }^{2}$.

\footnotetext{
2 For example, in a system of four regions, and with region $i$ neighbouring two out of three $j$ s, weights assigned are 0 for the region itself, 0 for regions with which it does not neighbour, and one for each neighbour,
} 
As a start, an OLS spatial cross sectional model ${ }^{3}$ is estimated without considering spatial lag terms which control of spatial autocorrelation effects of the dependent variable. This estimation is followed by testing for spatial dependence. First, spatial correlation of the cross sectional regression residuals is tested using the Moran's I spatial statistic as per the following equation:

$M I=\frac{(n-1) \sum_{i=1}^{n} \sum_{j=1}^{n} w_{i j} \varepsilon_{i} \varepsilon_{j}}{\sum_{i=1}^{n} \varepsilon_{i}{ }^{2}}$

Further, spatial correlation is tested using the Moran's I conducted for the dependent variable, as per the following equation:

$$
M I=\frac{(n-1) \sum_{i}^{N} \sum_{j}^{N} w_{i j}\left(y_{i}-\bar{y}\right)\left(y_{j}-\bar{y}\right)}{\sum_{i}^{N} \sum_{j}^{N} w_{i j}\left(y_{i}-\bar{y}\right)^{2}}
$$

Where $\mathrm{w}_{i j}$ is the element of the spatial weights matrix, $i=1,2, \ldots, 27, j=1,2, \ldots, 27$, and $\mathrm{m}=\mathrm{n}$ or $\mathrm{m} \neq \mathrm{n}$. The significance of the Moran's I of both the regression residuals and of the dependent variable is tested by the Z-score.

Upon establishing significance of the dependent variable's and residual spatial correlation, spatial models are estimated in a manner that controls for the spatial autocorrelation effects, and are estimated using maximum likelihood method. Specifications of spatial models vary. On the one hand, the spatial Durbin model (SDM) accounts for the spatial autocorrelation of the dependent variable by incorporating an average value of the independent variable $(x)$ in neighbouring region(s). This is, in turn, associated with the weight matrix $\left(\mathrm{y}_{\mathrm{i}}=\beta x_{\mathrm{i}}+\theta \mathrm{W} x_{j}+\mu\right)$, and $\mu$ is assumed to behave normally. On the other hand, the spatial autoregressive model (SAR) regresses levels of $y$ in region $i$ on levels of $y$ in neighbouring region(s) $j$ (thereby accounting for the dependent variable's spatial autocorrelation by incorporating values of the dependent variable in the regions which it neighbours). Thus, the model allows for spill-overs of $y$ from $j$ into $i$ ( $\mathrm{y}_{i}=\beta x_{i}+\lambda \mathrm{W}_{\mathrm{j}}+\mu$, and $\mu$ is assumed to behave normally. The spatial error model (SEM) incorporates the dependent variable's spatial autocorrelation through the error term, such that $y_{\mathrm{i}}=\beta x_{i}+\mu$, $\mu=\lambda \mathrm{W} \mu_{i}+\nu$, where $\nu$ is assumed to behave normally. Finally, the general spatial model (usually denoted by SAC) combines the SAR and the SEM models.

If the significance of the dependent variable, and of the residuals, spatial correlation is not established, then the data for the regions would not show spatial dependence, but rather spatial randomness. In this case, a panel data model is estimated without considering spatial lag terms. In this case, a dynamic panel data model would be estimated using the

summing to 2 . Row weights would be $1 / 2$ for each of the two regions that $i$ neighbours, 0 for region $i$ itself, and 0 for the non-neighbour region. There are four criteria for considering regions to be 'neighbours': 1) whether they share (part of) a common eastern or western border (Linear contiguity); 2) whether they share part of a common border on any side for a small distance (Rook contiguity); 3) whether they meet at a point (even less than the snapshot distance) (Bishop contiguity); 4) whether they share any part of common border (Queen contiguity - union of the Rook and the Bishop). Spatial weights matrices, testing for OLS residual spatial correlation, and estimation of cross sectional SAR, SEM and SAC models, are carried out using GeoDa open source software. GeoDa constructs the spatial weights matrix using geographical attributes given in ESRI shape files provided by a nation's Survey Authority. For Egypt, shape files are provided by The Central Agency for Public Mobilization and Statistics (CAPMAS).

${ }^{3}$ Same method is applied for panel data models. Also in case of suspected endogeneity of dependent and one or more of the independent variables, estimation is conducted as a generalized method of moments (as in results shown in table 2 ) 
generalized method of moments.

\subsection{Data Description}

Data for the dependent variable $\boldsymbol{C O}_{2}$ emissions by governorate are not readily available for Egypt. A proxy variable was derived as the share of the nominal value of output (at selling price) of energy-intensive polluting activities of the governorate in the total nominal value of output of energy-intensive polluting industries nation-wide. Energyintensive polluting industries are, namely, mining, and polluting manufacturing industries. ${ }^{4}$ Each governorate's share is multiplied by total nation-wide $\mathrm{CO}_{2}$ (emissions resulting from the burning of fossil fuels in consumption or in gas flaring, measured in millions of metric tonnes) gives a proxy of $\mathrm{CO}_{2}$ emissions by governorate. ${ }^{5} \mathbf{C O}_{2}$ emissions per capita is obtained as the $\mathrm{CO}_{2}$ emissions by governorate divided by the governorate population.

Net fixed capital formation for industry (mining and manufacturing industries) is among the variables that commonly affect carbon dioxide emissions level at the regional level, (see Sodersten et al.,2017; and Wensong et al., 2018). Net fixed capital formation is defined as gross fixed capital formation minus depreciation of existing capital, hence, reflecting the net addition to capital. The expected sign is positive if investments are concentrated in polluting industries. However, when investors are using environmentally-friendly techniques of production, the expected sign is negative. It is measured in nominal value.

Population density also affects pollution emissions level. It is defined as the ratio of population of the governorate to its area, measured per squared $\mathrm{km}$. The expected sign of this variable is indistinct. This is because, on the one hand, the sign is expected to be positive if we consider the scale effect in which the needs of a populous region are met through large scale production. Consequently, the more the production is, the higher the pollution emissions will be. This is definitely magnified if firms use traditional polluting techniques of production. On the other hand, the expected sign is negative if improvements in technology in urban areas that are usually highly populated result in a reduction in pollution emissions level (Wensong et al., 2018).

This variable is omitted from the set of independent variable in this model since the dependent variable is defined as $\mathbf{C O}_{2}$ emissions per capita for high possibility of endogeneity.

Females in working age population is defined as the share of females in the working age population (15-64). This variable is added to test for the effect of the gender composition of population in Egypt's governorates on $\mathrm{CO}_{2}$ emissions level. Indeed, contemporary literature such as Brough et al. (2016) suggest that females are more environmentally conscious than males ${ }^{6}$, in which case the expected sign is negative, and

\footnotetext{
${ }^{4}$ Many studies show that there is a strong correlation between energy use and CO2 emissions level. For more information, see Gao and Zhang (2014) and Hassaballa (2011).

${ }^{5}$ Polluting industries as identified based on their actual emissions intensity per unit of output. Manufacturing industries ranked in order of pollution intensity are: ferrous and non-ferrous basic metals; industrial chemicals, refined petroleum products, nonmetallic mineral products, paper and pulp, rubber, leather, and fabricated metal products except machinery. Of the above industries, all except leather products are energy-intensive. Thus, almost all polluting industries are themselves energy-intensive.
}

6 For more information, see "Global Women's Issues: Women in the World Today, extended version", Chapter 11, 2012. 
Sundström and McCright (2014).

In addition, the educational level can reflect the degree of environmental awareness per region. ${ }^{7}$ Three variables are used to assess whether higher education may be associated with greater environmental awareness, hence an expected positive effect on environmental quality: illiterates in working age population; intermediate degree holders in working age population; university degree holders in working age population which is defined as the share of illiterates, intermediate degree holders, university degree holders in the working age population (15-64), respectively. The expected sign is positive for illiterates, as perhaps illiterates are expected to lack awareness. The expected sign is negative for intermediates and university degree holders as individuals may become more aware of the hazards of environmental degradation with higher levels of education.

Furthermore, the type of activity that the region specializes in is believed to affect the level of $\mathrm{CO}_{2}$ emissions (Wensong et al., 2018). For lack of data for value added of industrial, agricultural and service activities by region, three proxy variables are used to reflect the dominance of an economic activity in a region: industry, agriculture, and services employed in total employed in each governorate. These three variables are defined as the share of those employed in industry (mining and manufacturing), in agriculture and in services in the total number of employed labour force members in the governorate, respectively. The expected signs of the three variables are either positive if firms use polluting techniques in their production or negative if they adopt environmentally friendly techniques of production which could be due to stringent environmental regulations. For instance, if an emission standard is imposed, farmers may shift to planting less polluting crops instead of more polluting ones resulting in a decline in pollution emissions level (Some et al., 2017).

Finally, Road network density effect on carbon dioxide emissions level is also considered. Road network density is the ratio of total road length of the governorate to its geographical area in $\mathrm{km}^{2}$. The expected sign is negative because a higher road network density will result in less congestion which in return leads to less environmental damages from car exhausts, holding other things constant (Wensong et al. ,2018). A Summary of the study variables and their expected signs are shown in table 1.

Table 1: Model Variables

\begin{tabular}{|c|c|c|c|}
\hline Variable & Name & Description & Sign \\
\hline PCCO2_emiss & $\begin{array}{l}\mathrm{CO}_{2} \text { emissions per } \\
\text { capita }\end{array}$ & $\begin{array}{l}\text { is obtained as the } \mathrm{CO}_{2} \text { emissions by } \\
\text { governorate divided by the governorate } \\
\text { population. }\end{array}$ & $\begin{array}{l}\text { Dependent } \\
\text { variable }\end{array}$ \\
\hline PCCO2_emiss_1 & $\begin{array}{l}\text { Lagged } \mathrm{CO}_{2} \\
\text { emissions per capita }\end{array}$ & $\begin{array}{l}\text { is obtained as the } \mathrm{CO}_{2} \text { emissions by } \\
\text { governorate divided by the governorate } \\
\text { population in the previous period }\end{array}$ & $\begin{array}{l}\text { Positive or } \\
\text { negative }\end{array}$ \\
\hline NFKF & $\begin{array}{l}\text { Net fixed capital } \\
\text { formation }\end{array}$ & $\begin{array}{l}\text { is defined as gross fixed capital formation } \\
\text { minus depreciation of existing capital, } \\
\text { hence, reflecting the net addition to } \\
\text { capital. }\end{array}$ & $\begin{array}{l}\text { Positive or } \\
\text { negative }\end{array}$ \\
\hline FWAge & Females in working & is defined as the share of females in the & Negative \\
\hline
\end{tabular}

7 See Global Education Monitoring Report by the UNESCO at https://gemreportunesco.wordpress.com /2015/12/08/education-increases-awareness-and-concern-for-the-environment/ 


\begin{tabular}{|l|l|l|l|}
\hline & age population & working age population (15-64 & illtW Age \\
UniW Age & $\begin{array}{l}\text { illiterates in working } \\
\text { age population; } \\
\text { university degree } \\
\text { holders in working } \\
\text { age population }\end{array}$ & $\begin{array}{l}\text { is defined as the share of illiterates, } \\
\text { university degree holders in the working } \\
\text { age population (15-64), respectively }\end{array}$ & $\begin{array}{l}\text { Positive for } \\
\text { illiterates } \\
\text { Negative for } \\
\text { university } \\
\text { degree holders }\end{array}$ \\
\hline $\begin{array}{l}\text { IndEmp, } \\
\text { AgrEmp } \\
\text { ServEmp }\end{array}$ & $\begin{array}{l}\text { and services } \\
\text { employed in total } \\
\text { employed in each } \\
\text { governorate. }\end{array}$ & $\begin{array}{l}\text { are defined as the share of those } \\
\text { employed in industry (mining and } \\
\text { manufacturing), in agriculture and in } \\
\text { services in the total number of employed } \\
\text { labour force members in the } \\
\text { governorate, respectively. }\end{array}$ & $\begin{array}{l}\text { Positive or } \\
\text { negative }\end{array}$ \\
\hline RdNetw & Road network density & $\begin{array}{l}\text { is the ratio of total road length of the } \\
\text { governorate to its geographical area in } \\
\text { km². }\end{array}$ & Negative \\
\hline
\end{tabular}

Source: Designed by the authors

\subsection{Data Sources}

Data on $\mathrm{CO}_{2}$ emissions are obtained from the World Development Indicators by the World Bank. Output and net fixed capital formation data, on the governorate level, are obtained from CAPMAS Annual Bulletin of Industrial Production Statistics (2007-2016), and population data are drawn from the statistical yearbook issued annually by CAPMAS (2007-2016). Data on the governorate level for females, illiterates, university degree holders, the working age population, industry employed, agriculture employed, and services employed are utilised from the Annual Statistical Bulletin of the Labour Force Survey in Egypt issued annually by CAPMAS (2007-2016). Road network density data are drawn from the Annual Bulletin of Statistics on Roads and Bridges issued annually by CAPMAS (2007-2016). Stata is the software used in the estimation.

\section{Estimation results}

An OLS spatial cross-section model is estimated for each of the years of study. Moran's I (error) tests are performed to assess the availability of spatial autocorrelation of the residuals from the estimated equations. Test results are given in Table 2 below:

Table 2: Moran's I (error) diagnostic test for weights matrix of the governorates of Egypt (row-standardized weights), 2007-2016

\begin{tabular}{|c|c|c|c|c|c|c|c|}
\hline Summary of & tput & : Leas & squares est & ation & & & \\
\hline Data set & & : egy & admbnda_a & n1_capmas_ & 70421 & & \\
\hline Dependent & iable & : PC & O2_emiss & Num & of Observa & ations: & 27 \\
\hline Mean depen & t variable & $: 0.01$ & & Num & of Variable & es & 10 \\
\hline S.D. depend & variable & $: 0.0$ & & Degr & of Freedom & : & 17 \\
\hline $\begin{array}{l}\text { Regression } \\
\text { Year }\end{array}$ & Moran's I & $\begin{array}{l}\text { Z- } \\
\text { score }\end{array}$ & $\begin{array}{l}\mathrm{p}^{-} \\
\text {value }>|\mathrm{Z}|\end{array}$ & $\begin{array}{l}\text { Regression } \\
\text { Year }\end{array}$ & Moran's I & $\begin{array}{l}\text { Z- } \\
\text { score }\end{array}$ & $\begin{array}{l}\mathrm{p}^{-} \\
\text {value }>|\mathrm{Z}|\end{array}$ \\
\hline 2007 & 0.263 & -1.027 & 0.30 & 2012 & -0.191 & -1.025 & 0.31 \\
\hline 2008 & -0.131 & 0.645 & 0.52 & 2013 & -0.180 & -0.940 & 0.35 \\
\hline 2009 & -0.058 & -0.080 & 0.94 & 2014 & 0.097 & 1.308 & 0.19 \\
\hline
\end{tabular}




\begin{tabular}{|l|l|l|l|l|l|l|l|}
\hline $\mathbf{2 0 1 0}$ & -0.196 & -1.084 & 0.28 & $\mathbf{2 0 1 5}$ & 0.086 & -0.316 & 0.75 \\
\hline 2011 & -0.029 & 0.275 & 0.78 & $\mathbf{2 0 1 6}$ & -0.140 & -0.834 & 0.40 \\
\hline
\end{tabular}

Source: Authors' Computations

P-values indicate that the test statistics for all Moran I's are not statistically significant pointing to the absence of spatial autocorrelation of the residuals. Hence, there is no spatial dependence between neighbouring regions in $\mathrm{CO}_{2}$ emissions per capita in Egypt, but spatial randomness instead. Upon further testing for spatial autocorrelation of the dependent variable $\left(\mathrm{CO}_{2}\right.$ emissions per capita), the Moran's I is also not significant for all the years of study, providing further evidence for spatial randomness. Test results are given Table 3:

Table 3: Moran's I ( $\mathrm{CO}_{2}$ emissions per capita) diagnostic test for weights matrix of the governorates of Egypt (row-standardized weights), 2007-2016

\begin{tabular}{|c|c|c|c|c|c|c|c|}
\hline Year & Moran's I & Z-score $(\mathrm{I})$ & $\mathrm{p}$-value $>|\mathrm{Z}|$ & Year & Moran's I & Z-score $(\mathrm{I})$ & $\mathrm{p}$-value $>|\mathrm{Z}|$ \\
\hline 2007 & -0.105 & -0.590 & 0.32 & 2012 & -0.042 & 0.092 & 0.38 \\
\hline 2008 & -0.048 & 0.054 & 0.42 & 2013 & -0.049 & 0.049 & 0.40 \\
\hline 2009 & -0.028 & 0.260 & 0.37 & 2014 & -0.027 & 0.157 & 0.35 \\
\hline 2010 & -0.046 & 0.089 & 0.35 & 2015 & -0.102 & -0.691 & 0.25 \\
\hline 2011 & -0.056 & -0.020 & 0.43 & 2016 & -0.069 & -0.304 & 0.45 \\
\hline
\end{tabular}

Source: Authors' Computations

The spatial randomness evident from both tests does not agree with most empirical findings for other countries which find that $\mathrm{CO}_{2}$ emissions (level and per capita) are highly spatially dependent (see for example, Wensong et al. 2018; Yang et al. 2019; Zhao et al. 2014). It is therefore important to understand why such spatial randomness of $\mathrm{CO}_{2}$ emissions per capita may exist in Egypt.

As a start, Figure 2 represents spatial randomness as the dispersed dark squares which have no pattern of clustering.

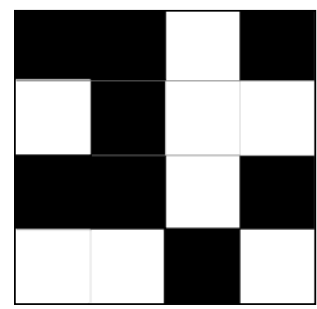

Figure 2: Representation of spatial randomness

Source: https:// www.statisticshowto.com/morans-i/

The representation of spatial randomness in Figure 2 corresponds with the average 2007$2016 \mathrm{CO}_{2}$ emissions per capita for the governorates of Egypt shown in Figure 3. This is apparent for the four governorates which fall in the highest (darkest shaded) emissions per capita quantile (Matrouh, Suez, South Sinai and Red Sea). Relative to 2007-2016 average nation-wide level of $\mathrm{CO}_{2}$ emissions, the share of the average $\mathrm{CO}_{2}$ emissions in 2007-2016 is $12 \%$ in Matrouh; 11\% in the Red Sea; 4\% in South Sinai; and 5\% in Suez (Source: authors' computations). Reasons underlying these shares include the existence of highly polluting activities in each of these governorates: Matrouh (extraction of crude petroleum); Red Sea (extraction of crude petroleum and quarrying of non-ferrous metals (e.g., phosphates)); 
South Sinai (extraction of oil and gas, and quarrying of stones, sand and clay); Suez (petroleum refining, non-metallic mineral products, basic metals, industrial chemicals, metal processing).

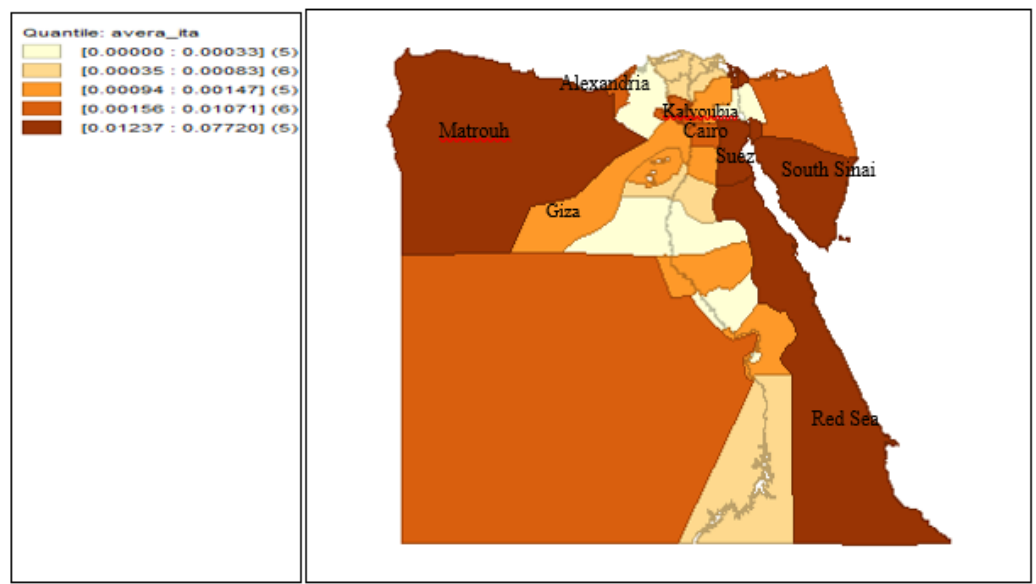

Figure 3: Map of 2007-2016 average $\mathrm{CO}_{2}$ emissions per capita for the governorates of Egypt

Source: Authors' Computations

The aforementioned Moran's I test statistics for the residuals of the cross sectional regression equations for all the years of study (2007 through 2016), and for $\mathrm{CO}_{2}$ emissions per capital are found to be insignificant. Also, spatial randomness in CO2 emissions is evident from Figure 3. Therefore, using the spatial specification for estimating CO2 emissions per capita equation for Egypt is not appropriate. A dynamic panel data model is estimated using the Arellano and Bond generalized method of moments. With all the explanatory variables are transformed by differencing, and estimation is done using the generalized method of moments, this method achieves greater efficiency in estimation compared to the simpler instrumental variable estimation (Roodman, 2009).

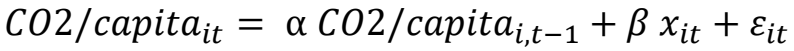

where $i=1,2, \ldots, 27, t=1,2, \ldots, 10$, and $x_{i t}$ denotes the independent variables of governorate $i$ at time $t$, and $\varepsilon_{i t}$ is assumed to behave normally.

Because there is an expected perfect collinearity between the three variables used as proxies for the economic activity (employment in industry, agriculture and services), two models are estimated. Model (1) includes industry and services, and model (2) includes industry and agriculture. Results of model (1) and model (2) estimations are given in 4.

Table 4: Arellano and Bond Difference GMM

\begin{tabular}{|c|c|c|c|c|}
\hline \multicolumn{5}{|c|}{ Dependent Variable: PCCO2_emiss } \\
\hline & \multicolumn{2}{|c|}{ Model (1) } & \multicolumn{2}{c|}{ Model (2) } \\
\hline Variables & Coefficient & t-statistic & Coefficient & t-statistic \\
\hline PCCO2_emiss_1 & $1.701^{* * *}$ & 27.95 & $1.696^{* * *}$ & 28.43 \\
\hline NFKF & $1.19 \mathrm{e}-09^{*}$ & 1.90 & $1.23 \mathrm{e}-09^{*}$ & 2.01 \\
\hline RdNetw & -0.001 & -0.71 & -0.001 & -0.71 \\
\hline FWAge & $-0.657^{*}$ & -1.99 & $-0.689^{* *}$ & -2.14 \\
\hline IlltWAge & $0.598^{*}$ & 2.03 & $0.625^{* *}$ & 2.17 \\
\hline
\end{tabular}




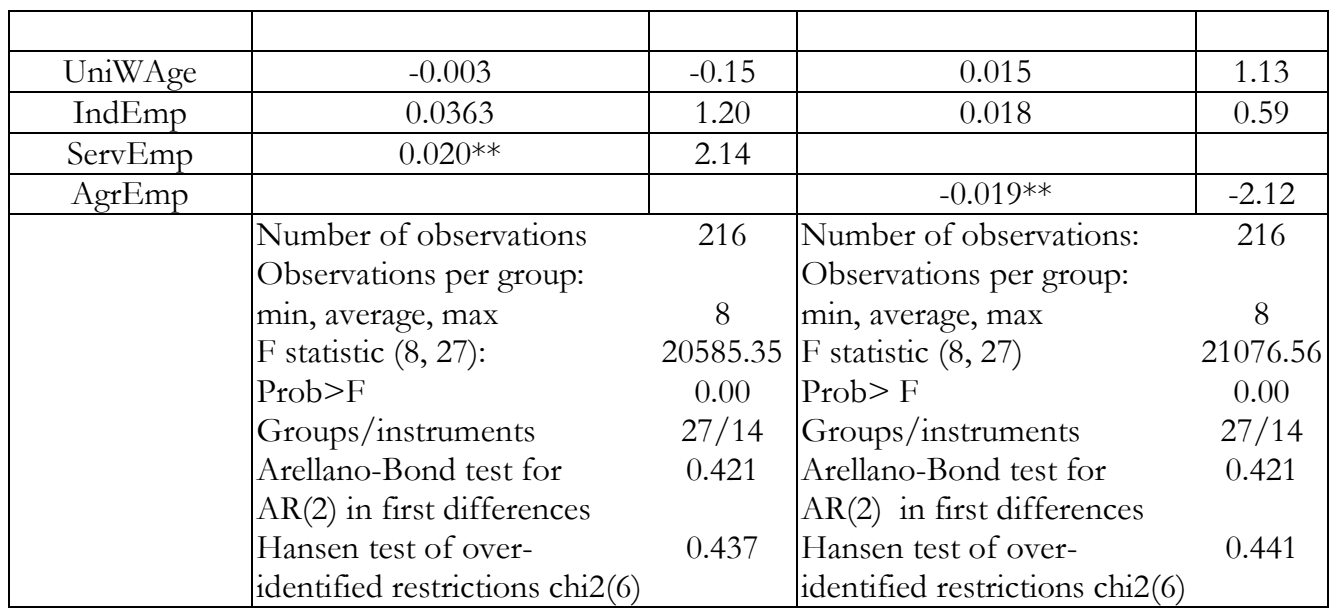

Notes: $* * *, * *, *$ are statistically significant at $1 \%, 5 \%$, and $10 \%$, respectively; p-values reported for AR (2) and Hansen Statistic.

Source: Authors' Computations.

The $\operatorname{AR}(2)$ is found to be statistically insignificant indicating that the model is not suffering from second order serial correlation. In other words, the second lags used as instruments are not correlated with the error term. Further, the insignificant Hansen statistic indicates that the instruments used in the model are valid, and thereby the model does not suffer from over-identification of instruments.

The coefficients obtained from GMM estimates are the short run coefficients. In model (1), a one percent increase in $\mathrm{CO}_{2}$ emissions per capita in previous period is associated with a $1.7 \%$ increase in present period $\mathrm{CO}_{2}$ emissions per capita in the short run at a $1 \%$ level of significance, ceteris paribus. Thus, the deterioration of environmental quality is highly associated with previous period $\mathrm{CO}_{2}$ emissions per capita. This also indicates that there is persistence in $\mathrm{CO}_{2}$ emissions.

A one percent increase in net fixed capital formation is associated with $1.2 \mathrm{e}-09 \%$ increase in $\mathrm{CO}_{2}$ emissions per capita in the short run at a $10 \%$ level of significance, ceteris paribus. This effect of net fixed capital formation is indeed of an extremely small magnitude. However, the statistical significance indicates that investments in Egypt were, as may be expected, heavily and primarily concentrated in polluting (energy intensive) economic activities.

A one percent increase in the share of females in working age population is associated with a $0.66 \%$ decrease in $\mathrm{CO}_{2}$ emissions per capita in the short run at a $10 \%$ level of significance. This result is in line with literature, indicating a relatively high environmental awareness among females as suggested by Sundström and McCright (2014) and Brough et al. (2016). ${ }^{8}$ However, illiterates share in the working age population's effect is opposite to that of females. A one percent increase in the share of illiterates in the working age population is associated with a $0.59 \%$ increase in $\mathrm{CO}_{2}$ emissions per capita in the short run at a $10 \%$ level of significance.

8 See “Global Women's Issues: Women in the World Today, extended version”, Chapter 11, 2012, for more information. 
It is worth noting that the result for university degree holders in model (1), though not statistically significant, but does show a negative effect on $\mathrm{CO}_{2}$ emissions per capita. As such, one may conclude that illiterates, as may be expected, lack environmental awareness, while university degree holders may be more environmentally conscious.

The effect of services' shares in total employed is significant and positive in model (1). A one percent increase in the share of services employed is associated with a $0.02 \%$ increase in $\mathrm{CO}_{2}$ emissions per capita in the short run at a $5 \%$ level of significance ceteris paribus. Meanwhile, in model (2) agriculture share of the total employed is found to decrease $\mathrm{CO}_{2}$ emissions per capita, such that a one percent increase in the share of agriculture employed is associated with a $0.02 \%$ decrease in $\mathrm{CO}_{2}$ emissions per capita in the short run at a $5 \%$ level of significance. Thus, services and agriculture are found to have opposing effects on $\mathrm{CO}_{2}$ emissions per capita.

Finally, though not statistically significant in either model (1) or (model (2), the coefficient of industry employed is positive. This may indicate that industrial firms (both of mining and manufacturing activities) are using polluting techniques in their production (Hassaballa, 2011; Mercian et al. 2007).

As for the road network density, the negative sign on coefficient would be in line with the literature suggesting that a higher road network density reduces congestion which, in turn, may reduce environmental damages from car exhausts, holding other things constant (Wensong et al.,2018; Liu, 2019). For a discussion of long run coefficients, see table A2 in the appendix.

\section{Conclusion and Policy Implications}

The current research tested for the existence of spatial dependence of $\mathrm{CO}_{2}$ emissions for the twenty-seven governorates of Egypt over the period 2007-2016 utilising a generalized method of moments dynamic panel model. Results revealed that $\mathrm{CO}_{2}$ emissions are not spatially dependent and are spatially random. The lag of $\mathrm{CO}_{2}$ emissions per capita, net fixed capital formation, share of illiterates in the working age population, and the share of services in economic activity are found to be statistically significant and positively affects $\mathrm{CO}_{2}$ emissions. In contrast, the share of females in working age population, and the share of agriculture in economic activity are statistically significant and of a negative effect.

Reducing $\mathrm{CO}_{2}$ emissions level should be top priority for policy makers in Egypt, particularly in the light of the current results that show multiple factors contributing to its rise. The contribution of these factors is magnified due to the persistence of $\mathrm{CO}_{2}$ emissions level. Persistent $\mathrm{CO}_{2}$ emissions are an indication of little serious effort being made towards pollution reduction. Hence, shifting to a green economy pathway is advisable to achieve this target. For instance, it has been estimated by the UNEP (2015) that more than US\$1.3 billion will be saved in the agriculture sector in addition to saving of US $\$ 1.1$ billion in the water sector per year if Egypt shifts to a green economy. Furthermore, most importantly, there will also be a decline in $\mathrm{CO}_{2}$ emissions level by 13\% (UNEP (2015)).

In addition, the positive contribution of net fixed capital formation indicates that investments result in further environmental degradation. To tackle this problem, the Egyptian government should enforce stringent environmental regulations. At the same 
time, it should provide financial and technical assistance to motivate polluting firms to abide by the legal standards. The government should further incorporate the environmental dimension in its decisions at the macro level. Likewise, firms should adopt a holistic environmental management system. In such system, firms can easily achieve their environmental objective and improve their environmental performance through regular review and evaluation (Hassaballa, 2011).

Moreover, the results highlighted that illiterates contribute positively to the rise of $\mathrm{CO}_{2}$ emissions level, making it imperative to fight illiteracy. For illiteracy among children, the government should use all the possible channels such as public and social media to raise awareness about the importance of educating children. In addition, it should enforce strict penalties on child labour. A review of the educational curricula is essential to avoid high drop-out rates. Aiming to enable families and to prevent their heavy reliance on child labour, the government is well-advised to ease credit availability to the poor.

As for adult illiteracy, identifying the number of illiterates in each district, and each sub-district, is much needed. In doing so, it would be possible to target their illiteracy eradication over a given time line. Rewarding and incentivizing adults who succeed in attaining "read and write" status at old age is highly recommended.

It may be counterintuitive that the services sector increases environmental degradation. However, this could, in fact, be the effect of the type of dominant service activities. For instance, the services sector can be polluting if it is dominated by tourism, and healthcare sectors. If environmental regulations in tourism are lax, environmental degradation may result. Also, if healthcare sector is disposing of wastes through open burning and incineration, this would be of further environmental damage.

Finally, the results showed positive contribution of female and the agricultural sector to environmental quality. Thus, it is very important to transfer this environmentally friendly attitude of females to their children, husbands and the rest of the population at large. As for the agricultural sector, this sector should be studied in depth to identify the causes of this environmentally friendly result. This is to evaluate whether it could be replicated in other sectors or not.

\section{References}

Akbostanc1, E., Tunc, G., Turut-Asik, S. (2011). CO2 emissions of Turkish manufacturing industry: A decomposition analysis. Applied Energy, 88, 2273-2278.

Anselin, L. (1991). Handbook of regional and urban economics. In: Nijkamp P (ed), Volume 1: Regional economics (North-Holland, Amsterdam, 1986). Regional Science and Urban Economics 21(1), 143-156

Anwar, A., Younis, M., and Ullah, I. (2020). Impact of Urbanization and Economic Growth on $\mathrm{CO}_{2}$ Emission: A Case of Far East Asian Countries. . International Journal of Environmental Research and Public Health, $17,2531$.

Aragon, J. \& Miller M. (2012). Global Women's Issues in the World Today, Extended Version, Bureau of International Information Programs, United States Department of State.

Azimi, M., \& Yang, F. F. (2018). Air Pollution Inequality and Its Sources in SO2 and NOX Emissions among Chinese Provinces from 2006 to 2015. Sustainability, 10, 367.

Balado-Naves, R., Baños-Pino, J. F., \& Mayor, M. (2018). Do countries influence neighbouring pollution? A spatial analysis of the EKC for CO2 emissions. Energy Policy, 123, 266-279.

Brough, A.R., Wilkie, J. E. B. , Ma, J., Isaac, M. S., and Gal D. (2016). Is Eco-Friendly Unmanly? The GreenFeminine Stereotype and Its Effect on Sustainable Consumption, Journal of Consumer Research, 43, $567-582$. 
Burnett J., and Bergstrom, J. (2010). U.S. state-level carbon dioxide emissions: a spatial-temporal econometric approach of the environmental Kuznets curve. Faulty Series \#96031 from Department of Agricultural and Applied Economics, University of Georgia

Cai, F. (2008). Lewis turning point: a coming new stage of China's economic development. Social Sciences Academic Press, China

Cole, M. A., Elliott, J.R., Okubo, T., and Zhou, Y. (2013). The carbon dioxide emissions of firms: A spatial analysis, Journal of Environmental Economics and Management, 5, 290-309.

Elhorst, P. (2012). Dynamic spatial panels: models, methods, and inferences, Journal of Geographical Systems 14, $5-28$

Elliott, J., \& Clement, M. (2014). Urbanization and Carbon Emissions: A Nationwide Study of Local Countervailing Effects in the United States. Social Science Quarterly, 95(3), 795-816.

Environmental Performance Index in 2018. Available at https:// epi.yale.edu/downloads/epi2018policymaker ssummaryv01.pdf

Environmental Performance Index in 2020. Available at https://epi.yale.edu/downloads/epi2020report 20200911.pdf

Fang, C., Liu, H., Guangdong, L., Sun, D., and Miao, Z. (2015). Estimating the Impact of Urbanization on Air Quality in China Using Spatial Regression Models. Sustainability, 7(11), 15570-15592.

Friedl, B., Getzner, M. (2003). Determinants of $\mathrm{CO}_{2}$ emissions in a small open economy. Ecological Economics 45, 133-148

Gangodagamage, C., Zhou, X., and Lin, H. (2008). Autocorrelation, Spatial. In: Shekhar S., Xiong H. (eds) Encyclopedia of GIS. Springer, Boston, MA. Available at https://doi.org/10.1007/978-0-38735973-1_83.

Gao, J. and Zhang, L. (2014). Electricity consumption-economic growth- $\mathrm{CO}_{2}$ emissions nexus in SubSaharan Africa: Evidence from panel cointegration, African Development Review, 26, 359-371.

Goodchild, M. (1992). Geographical information science. International Journal of Geographic Information Systems, 6, $31-45$.

Grossman, G., and Krueger, A. (1991). Environmental impacts of a North American free trade agreement. NBER Working Paper 3914.

Hassaballa, H. (2011). Environment and foreign direct investments: An empirical investigation. PhD Thesis, Faculty of Economics and Political Science, Cairo University.

Jeanty, P., Malin E., Donfouet, P. (2013). A spatial dynamic panel analysis of the environmental Kuznets curve in European. Center for Research in Economics and Management.

Jeetoo J. (2020). Spillover effects in public healthcare expenditure in Sub-Saharan Africa: A spatial panel analysis, African Development Review, 32, 257-268.

Lin, B., Jiang, Z. (2009). EKC forecasting and driving forces of China's CO2. Management Science, 4, 27-36

Liu, H., and Zhao, H. (2012). The regional differences of $\mathrm{CO}_{2}$ intensity in China. Stat Res, 6: 46-50. In Zheng, X., Yu, Y., Wang J., Deng, H. (2014) Identifying the determinants and spatial nexus of provincial carbon intensity in China: a dynamic spatial panel approach. Regional Environmental Change, 1, 1651 166.

Liu, X. (2019). Effects of Urban Density and City Size on Haze Pollution in China: Spatial Regression Analysis Based on 253 Prefecture-Level Cities PM $_{2.5}$ Data", Discrete Dynamics in Nature and Society, vol. 2019, Article ID 6754704, 1-8 pages. Available at https://doi.org/10.1155/2019/6754704.

Lorember, P., Goshit, G. and Dabwor, D. (2020). Testing the nexus between renewable energy consumption and environmental quality in Nigeria: The role of broad-based financial development, African Development Review, 32, 163-175.

Merican, Y., Yusop, Z., Noor, Z. and Hook, N. (2007) Foreign direct investment and the pollution in Five ASEAN nations, International Journal of Economics and Management, 1, 245-261.

Nicolaisen, J., Dean, A., and Hoeller, P. (1991). Economics and the environment: A survey of issues and policy options. OECD Economic Studies No. 16.

Nsiah, C. and Wu, C., (2014). The role of spatial dynamics in the determination of foreign direct investment inflows to Africa, African Development Review, 26, 494-507.

Özokcu, S., and Özdemir, Ö. (2017). Economic growth, energy, and environmental Kuznets Curve. Renewable and Sustainable Energy Reviews, 72, 639-647. 
Panayotou, T. (1993). Empirical tests and policy analysis of environmental degradation at different stages of economic development World Employment Programme Research Working Paper WEP2-22/WP 238

Paul, S., and Bhattacharya, R. N. (2004). $\mathrm{CO}_{2}$ Emission from Energy use in India: a decomposition analysis, Energy Policy, 32, 585-593.

Roodman, David. (2009). How to do xtabond2: An introduction to difference and system GMM in Stata. The Stata Journal, 9, 86-136. Available at https://journals.sagepub.com/doi/pdf/10.1177/ 1536867 X0900900106

Schmalensee, R., Stoker, T., Judson, R. (1998). World carbon dioxide emissions: 1950-2050. The Review of Economics and Statistics, 80, 15-27.

S odersten, C.A., Wood, R., and Hertwich, E.G. (2017). Environmental impacts of capital formation, Journal of Industrial Ecology, 22, 1-13.

Some, T., Mbaye, A. and Barbier B. (2017). Greenhouse gas emission reduction in agriculture: Trade-off or win-win situation for small farmers in the Sudanian area of Burkina Faso?, African Development Review, 29, 163-178.

Sundström, A., and McCright, A. M. (2014). Gender differences in environmental concern among Swedish citizens and politicians, Environmental Politics, 23, 1082-1095.

Sun, J.W. (1998). Changes in energy consumption and energy intensity: A complete decomposition model. Energy Economics, 20, 85-100.

The Central Agency for Public Mobilization and Statistics 2018. Available at https://www.capmas.gov.eg/

The Central Agency for Public Mobilization and Statistics. Annual Bulletin of Industrial Statistics.

The Central Agency for Public Mobilization and Statistics. Annual Bulletin of Statistics on Roads and Bridges.

The United Nations Environment Programme (2015). Available at https://www.unenvironment.org/newsand-stories/press-release/egypt-save-over-us-24-billion-annually-cut-co2-emissions-13-water.

The United Nations Educational, Scientific and Cultural Organization, Global Education Monitoring Report. Available at https://gemreportunesco.wordpress.com/2015/12/08/education-increasesawareness-and-concern-for-the-environment/ (Accessed 15 September 2019)

The World Development Indicators. Available at http://datatopics.worldbank.org/world-development-indicators/

Wensong, S., L. Yanyan, W. Shaojian, Z. Yabo, S. Yongxian and L. Shijie (2018). Regional inequality, spatial spillover effects, and the factors influencing city-level energy-related carbon emissions in China, Journal of Geographical Sciences, 28, 495-513.

Xiaoyan, Z., Zhang, J., \& Li, J. (2013). Industrial Structure Transformation and Carbon Dioxide Emissions in China. Energy Policy, 57, 43-51.

Yang, W., Wang, W., and Ouyang, S. (2019). The influencing factors and spatial spillover effects of $\mathrm{CO}_{2}$ emissions from transportation in China, Science of the Total Environment, 696, 1-9.

Zhao, X., Burnett, J. W., \& Lacombe, D. J. (2014). Province-level convergence of China's carbon dioxide emissions. Applied Energy, 150, 286-295.

Zheng, X., Yu, Y., Wang J., Deng, H. (2014). Identifying the determinants and spatial nexus of provincial carbon intensity in China: a dynamic spatial panel approach. Regional Environmental Change, 14, 1651-1661.

\section{Appendix}

Table A1: Area, population, population density of the governorates of Egypt, 2019

\begin{tabular}{|lccc|}
\hline Governorate & Area $(\mathrm{sq} \mathrm{km})$ & Population & Population Density \\
\hline \hline Cairo & 3085.12 & 978,8739 & 3172.89 \\
Alexandria & 2300 & $5,299,718$ & 2304.23 \\
Port Said & 1344.96 & 764,499 & 568.42 \\
Suez & 9002.21 & 749,657 & 83.27 \\
Damietta & 910.26 & $1,539,075$ & 1690.81 \\
Dakahlia & 3538.23 & $6,679,368$ & 1887.77 \\
Sharkia & 4911 & $7,401,700$ & 1507.17 \\
Kalyoubia & 1124.28 & $5,792,066$ & 5151.80 \\
Kafr El-Sheikh & 3466.69 & $3,478,267$ & 1003.34
\end{tabular}




\begin{tabular}{|lccc|} 
Gharbia & 1942.34 & $5,146,411$ & 2649.59 \\
Menoufia & 2499 & $4,441,717$ & 1777.40 \\
Beheira & 9826 & $6,404,210$ & 651.76 \\
Ismailia & 5066.97 & $1,352,548$ & 266.93 \\
Giza & 13184 & $8,915,164$ & 676.21 \\
Beni Suef & 10954 & $3,288,219$ & 300.18 \\
Fayoum & 6068 & $3,747,942$ & 617.66 \\
Menia & 32279 & $5,745,212$ & 177.99 \\
Asyout & 25926 & $4,587,577$ & 176.95 \\
Sohag & 11022 & $5,193,052$ & 471.15 \\
Qena & 10798 & $3,302,894$ & 305.88 \\
Aswan & 62726 & $1,532,400$ & 24.43 \\
Luxor & 2409.68 & $1,296,540$ & 538.05 \\
Matrouh & 166563 & 461,847 & 2.77 \\
North Sinai & 28992 & 463,975 & 16.00 \\
South Sinai & 31272 & 105,953 & 3.39 \\
Red Sea & 119099.13 & 372,862 & 3.13 \\
El-Wadi El-Gedeed & 440098 & 249,399 & 0.57 \\
\hline
\end{tabular}

Source: Authors' computation based on data from Statistical Yearbook, CAPMAS, 2019.

\section{Long run relations:}

As a further step, it is customary to generate long run coefficients for those variables found to be statistically significant in the short run (as per results in Table ). The long run coefficient $\delta_{\mathrm{k}}$ is the long run effect, and is computed as $\delta_{\mathrm{k}}=\beta_{\mathrm{k}} /(1-\theta)$, where, $\beta_{\mathrm{k}}$ is the estimated short run coefficient of variable $\mathrm{k}$, while $\theta$ is the coefficient of the lagged dependent variable (PCCO2_emiss_1). The significance of $\theta$ (tested by a Z-score) would reflect whether the variable is significant in the long run and has the direction of the effect (positive or negative) as it does in the short run. The results are as follows:

Table A2: Long run effects of statistically significant variables on $\mathrm{CO}_{2}$ emissions per capita

\begin{tabular}{|c|c|c|c|c|}
\hline \multicolumn{5}{|c|}{ Dependent Variable: PCCO2_emiss } \\
\hline & \multicolumn{2}{|c|}{ Model (1) } & \multicolumn{2}{|c|}{ Model (2) } \\
\hline Variables with significant short run relation & Coefficient & Z-statistic & Coefficient & Z-statistic \\
\hline NFKF & $-1.70 \mathrm{e}-09 *$ & -1.90 & $-1.77 \mathrm{e}-09 * *$ & -2.01 \\
\hline FWAge & $0.938^{*}$ & 1.81 & $0.990^{*}$ & 1.94 \\
\hline IlltWAge & $-0.854^{*}$ & 2.17 & $-0.898^{* *}$ & -1.97 \\
\hline ServEmp & $-0.028 * * *$ & -2.61 & & \\
\hline AgrEmp & & & $0.028^{* * *}$ & 2.58 \\
\hline
\end{tabular}

Source: Authors' Computations.

All the variable coefficients are found to be statistically significant in the long run, ceteris paribus. In magnitude, Net fixed capital formation has about the same effect in long run as in the short run, but females, illiterate, services and agriculture have a larger long run than short run 
effect. In terms of direction of the effect, all coefficient changed signs, whereby net fixed capital formation has negative effect, females have a positive effect, illiterates have a negative effect, and services have a negative effect, while agriculture has a positive effect. The change in the direction of the effect is intriguing because it results from the coefficient of the dependent variable lagged being greater than one. In other words, for every per cent increase in the previous year's per capita $\mathrm{CO}_{2}$ emissions, the present year's per capita $\mathrm{CO}_{2}$ emissions increase by more than one percent. This effect is, in fact, reversing the effect of each of these variables in the long run compared to the short run. 